\title{
MATERNAL OUTCOME IN NEAR TERM REFERRAL CASES IN A TERTIARY CARE HOSPITAL
}

\author{
Archana Singh', T. Vijaya Krishna², H. Anupama ${ }^{3}$
}

${ }_{1}^{1}$ Assistant Professor, Department of Obstetrics and Gynaecology, Gandhi Medical College, Secunderabad.

${ }^{2}$ Assistant Professor, Department of Obstetrics and Gynaecology, Gandhi Medical College, Secunderabad.

3 Professor, Department of Obstetrics and Gynaecology, Gandhi Medical College, Secunderabad.

\section{ABSTRACT}

\section{BACKGROUND}

To describe maternal outcomes in near-term patients referred to a tertiary care hospital and to evaluate the reasons and impact of delay on the maternal outcomes.

\section{STUDY DESIGN}

Retrospective Observational Study.

\section{SETTINGS}

Gandhi Medical College, Secunderabad.

\section{STUDY POPULATION}

5086 cases referred to our tertiary care institute in one-year duration.

\section{DURATION}

June 2014 to May 2015.

\section{METHODOLOGY}

Scrutiny and analysis of medical records of the Obstetrics and Gynaecology Department of the hospital.

\section{Inclusion Criteria}

All referred antenatal cases to our tertiary care institute with more than 36 weeks' gestation and presenting with obstetric emergency were included in our study.

\section{MATERIAL AND METHODS}

Details including history, examination, investigations, indication for referral, mode of delivery, maternal outcome, maternal complications and their management were recorded.

\section{RESULTS}

The total number of referred cases with near-term gestation in above study period was 5086. The proportion of near-term referral cases, out of total admitted cases to the institute was $58.92 \%$. Most common reasons for referral besides socio-demographic reasons were repeat caesarean section, pre-eclampsia and eclampsia, prelabour rupture of membrane and anaemia. There were 41 maternal mortalities in the present study. This and other data collected provide valuable information about the impact of delayed referral.

\section{CONCLUSION}

Referral rates to tertiary care centre from various peripheral centres are alarmingly high. Repeat Caesarean Section and hypertensive disorders of pregnancy are the top most reasons for the referrals. The present study has shown that delay in referral is a big contributory factor for adverse maternal outcomes. There is an urgent need for $24 \mathrm{hrs}$. emergency obstetric care system with skilled obstetrician, paediatrician and anaesthetists at peripheral centres. The peripheral centres should be equipped with blood bank facilities and quick transportation facility should be readily made available to women in need.

\section{KEYWORDS}

Referred, Booked Cases, Tertiary Health Care, Maternal Morbidity and Mortality, Caesarean Section (LSCS), Spontaneous Vaginal Delivery (SPVD).

HOW TO CITE THIS ARTICLE: Singh A, Krishna TV, Anupama H. Maternal outcome in near term referral cases in a tertiary care hospital. J. Evolution Med. Dent. Sci. 2016;5(24):1291-1295, DOI: 10.14260/jemds/2016/302

Financial or Other, Competing Interest: None.

Submission 05-02-2016, Peer Review 06-03-2016,

Acceptance 11-03-2016, Published 23-03-2016.

Corresponding Author:

Dr. Archana Singh,

Department of Obstetrics and Gynaecology,

Gandhi Medical College, Musheerabad,

Secunderabad.

E-mail: dr_archanasingh@hotmail.com

DOI: 10.14260/jemds/2016/302

\section{INTRODUCTION}

Pregnancy and labour are considered a physiological process, but the potential for catastrophic complications are ever present and may develop in a matter of minutes. World over $5,58,000$ women die every year from such complications. Less than $1 \%$ of such deaths occur in developed countries. Around $99 \%$ of all maternal deaths occur in low and middle-income countries. These deaths are mainly attributed to Obstetric emergencies in developing countries. ${ }^{1}$ 
The disparity in the incidence demonstrates that maternal death is closely associated with socioeconomic status, educational background and social and cultural factors, but these factors are difficult to alter. Favourable outcome of unpredictable pregnancy complications and prevention of maternal mortality is extremely sensitive to obstetric care standards. However, many women in developing countries do not have access to health care with life-saving facilities to deal with such complications.

The purpose of antenatal care is to identify 'High Risk' cases as early as possible from a large group of antenatal mothers and arrange for them timely referral and appropriate management for obstetric emergencies during antenatal, intrapartum and postnatal period to reduce obstetric complications.

This is also the key step in reducing maternal morbidity and mortality. With this background, a retrospective study was undertaken at Gandhi Hospital to understand the incidence of Obstetric referral cases, their cause of referral, nature of complication, incidence of admission to the intensive care unit and final outcome including maternal deaths.

\section{AIM}

To study and analyse various near term obstetrics cases, which were referred from other centres and were admitted in Gandhi Hospital.

\section{OBJECTIVES}

1. To know the incidence of booked and unbooked referral cases in our hospital.

2. To review the primary reasons for referral to our hospital.

3. To study the clinical course of mother in the antenatal, intra-partum and postnatal period.

4. To know maternal outcome among referral cases and to document it.

\section{MATERIAL AND METHODOLOGY}

\section{Place of the Study}

This was a retrospective study undertaken at the Emergency Admission Centre, Department of Obstetrics and Gynaecology, Gandhi Hospital, Secunderabad, a tertiary care centre as well as one of the main referral centre and teaching hospital for the undergraduate and post graduate students. This hospital is a multispecialty and super speciality hospital with all the facilities available under a single roof. It has got an attached blood bank facility and is provided with an Intensive Neonatal Care Unit with $24 \mathrm{hrs}$. monitoring facility.

\section{METHODOLOGY}

Hospital records of obstetric admissions to the hospital for a period of 12 months from June 2014 to May 2015 were retrospectively reviewed. The total number of deliveries during this period was 11106 . The total number of referred cases in above study period was 5086. Data collected included patient's demographics, diagnosis, obstetric history, antenatal care status, previous morbid conditions, occurrence of lifethreatening conditions and first complication in the chain of events leading to these conditions and duration of hospitalization.

Data was also collected regarding patients who needed mechanical ventilation, their duration of stay in the ICU and patient outcome.

\begin{tabular}{|c|c|c|}
\hline Incidence & No. of Cases & Percentage \\
\hline Total near term cases & 8632 & \\
\hline Booked cases of GH & 3546 & $41.07 \%$ \\
\hline Referrals & 5086 & $58.92 \%$ \\
\hline & & Of total of Referral \\
\hline Unbooked referrals & 1859 & $21.53 \%(36.55 \%)$ \\
\hline Booked referrals & 3227 & $37.39 \%(63.45 \%)$ \\
\hline \multicolumn{2}{|c|}{ Table 1: Incidence of Cases in Twelve Months } \\
\hline
\end{tabular}

Out of total 8632 near term cases reported for a period of twelve months, 5086 cases met inclusion criteria which are about $58.92 \%$. The unbooked referral cases were 1859 making it $21.53 \%$ of total near term cases and $36.55 \%$ of referral cases. This indicates poor demographic conditions of the patients in the catchment area of hospital, which results in high number of unbooked term cases. The booked referral cases of other institutions were 3227 , which is $37.39 \%$ of total cases and $63.45 \%$ of referral cases.

\begin{tabular}{|c|c|c|}
\hline Time Interval & No. of Patients & Percentage \\
\hline$<6$ hrs. & 1853 & 36.43 \\
\hline 6 to $12 \mathrm{hrs}$. & 2226 & 43.77 \\
\hline 12 to $24 \mathrm{hrs}$. & 635 & 12.48 \\
\hline >24 hrs. & 372 & 7.32 \\
\hline $\begin{array}{c}\text { Table 2: Time Interval between Referral and } \\
\text { Reporting for Admission (For 5086 Referral Cases) }\end{array}$ \\
\hline
\end{tabular}

In only $36.43 \%$ of cases, the referral to reporting interval was less than $6 \mathrm{hrs}$. The percentage of cases where this interval is between $6-12 \mathrm{hrs}$. is as high as $43.77 \%$.

In majority (63.57\%) of the cases, the interval was more than $6 \mathrm{hrs}$.

\begin{tabular}{|c|c|c|}
\hline Cause & Number & Percentage \\
\hline Financial constraints & 897 & $48.25 \%$ \\
\hline Ignorance & 668 & $35.93 \%$ \\
\hline Transport problems & 138 & $7.42 \%$ \\
\hline Misc. & 156 & $8.39 \%$ \\
\hline $\begin{array}{c}\text { Table 3: Causes for not having Antenatal Check-ups in } \\
\text { Unbooked Referral Cases (Total Number of Cases-1859) }\end{array}$ \\
\hline
\end{tabular}

The biggest reason for not having antenatal check-ups among the referrals was due to lack of money or due to antenatal visit causing financial constraints, accounting for $48.25 \%$ of unbooked referral cases. The reason for $35.93 \%$ cases was ignorance and $7.42 \%$ had transport problems. Remaining $9.09 \%$ had miscellaneous problems like change of place, lack of family support, etc.

\begin{tabular}{|c|c|c|}
\hline Diagnosis & Number & Percentage \\
\hline $\begin{array}{l}\text { Normal (Demographic } \\
\text { referrals) }\end{array}$ & 1966 & 38.65 \\
\hline Previous caesarean section & 743 & 14.60 \\
\hline Pre-eclampsia \& eclampsia & 721 & 14.17 \\
\hline Prelabour rupture of membrane & 255 & 5.01 \\
\hline Anaemia & 249 & 4.89 \\
\hline IUGR & 212 & 4.17 \\
\hline Abruption & 186 & 3.65 \\
\hline Malpresentation & 134 & 2.63 \\
\hline Bad obstetrics history & 124 & 2.44 \\
\hline $\begin{array}{l}\text { Multifetal gestation/twin } \\
\text { pregnancy }\end{array}$ & 113 & 2.22 \\
\hline Foetal distress & 96 & 1.89 \\
\hline Intrauterine foetal death & 85 & 1.67 \\
\hline $\begin{array}{l}\text { Heart disease complicating } \\
\text { pregnancy }\end{array}$ & 31 & 0.61 \\
\hline Other medical disorders & 171 & 3.36 \\
\hline \multicolumn{3}{|c|}{ Table 4: Diagnosis at Admission for Referral Cases } \\
\hline
\end{tabular}


Out of total 5086 referral cases, 1966 (38.65\%) were not found with any disorder/complication. The largest cause of referral was previous LSCS (14.6\%) and pre-eclampsia/eclampsia (14.17\%). PROM, anaemia and IUGR each contributed between 4 to $5 \%$ of total referral. These causes indicate a need for strengthening the facilities to deal with such complication at secondary care centre.

\begin{tabular}{|c|c|c|c|c|c|}
\hline Type of Delivery & SPVD & LSCS & Forceps & Vacuum & Total \\
\hline Unbooked Referrals & $836(44.97 \%)$ & $658(35.39 \%)$ & $344(18.50 \%)$ & $21(1.12 \%)$ & 1859 \\
\hline Booked Referrals & $1226(39.20 \%)$ & $1338(42.78 \%)$ & $552(17.65 \%)$ & $11(0.35 \%)$ & 3127 \\
\hline Booked cases of GH & $2058(58.03 \%)$ & $1063(29.97 \%)$ & $421(11.87 \%)$ & $4(0.11 \%)$ & 3546 \\
\hline \multicolumn{7}{|c|}{ Table 5: Mode of Delivery for Referral Cases Total - 8632 Cases } \\
\hline
\end{tabular}

Booked referral had $42.78 \%$ LSCS deliveries and $39.20 \%$ vaginal deliveries compared to $35.39 \%$ and $44.97 \%$ for the same for unbooked referrals and $29.97 \%$ and $58.03 \%$ for Booked GH cases.

\begin{tabular}{|c|c|c|c|c|}
\hline & & \multirow{2}{*}{ Booked (GH) } & \multirow{2}{*}{ Booked Elsewhere } & \multirow{2}{*}{ Unbooked } \\
\cline { 4 - 5 } Condition & $\begin{array}{c}\text { Total } \\
\text { Cases }\end{array}$ & & 5 & 7 \\
\hline Rupture Uterus & 12 & 0 & 49 & 0 \\
\hline Caesarean Hysterectomy & 3 & 0 & 9 & 0 \\
\hline P.P.H & 58 & \multicolumn{2}{|c|}{ Table 6: Maternal Morbidity } \\
\hline
\end{tabular}

During the 12 months study, we had 12 cases of ruptured uterus all of which were Referrals. Among them 5 were booked from outside and 7 unbooked. All 3 cases of Caesarean Hysterectomy were referred cases booked outside. Among the 58 cases of PPH, 49 cases were unbooked and referred from outside. Remaining 9 cases were booked cases of Gandhi Hospital.

\begin{tabular}{|c|c|c|}
\hline Category & Number & Percentage \\
\hline Booked in GH & 7 & $12.06 \%$ \\
\hline Referral & 51 & $87.94 \%$ \\
\hline & 43 & Of total of Referral \\
Booked elsewhere & 8 & $74.14 \% 84.31 \%$ \\
Unbooked & \multicolumn{3}{|c|}{ Table 7: Cases Needing ICU Admission (58) } \\
\hline \multicolumn{2}{|c}{} \\
\hline
\end{tabular}

Out of 58 cases, 7 cases (12.06\%) were booked in GH and 51 cases $(87.94 \%)$ were referral cases. Most of the referral cases (43 (84.31\%)) were booked elsewhere and 8 were unbooked cases.

\begin{tabular}{|c|c|c|}
\hline Causes & $\begin{array}{c}\text { No. of } \\
\text { Cases }\end{array}$ & $\begin{array}{c}\text { Percentage } \\
\text { (\%) }\end{array}$ \\
\hline Hypertension & 24 & 41.37 \\
\hline $\begin{array}{c}\text { Haematological } \\
\text { conditions }\end{array}$ & 19 & 32.75 \\
\hline Heart disease & 10 & 17.24 \\
\hline Viral hepatitis & 2 & 3.44 \\
\hline AKI & 2 & 3.44 \\
\hline GBS & 1 & 1.76 \\
\hline \multicolumn{2}{|c|}{$\begin{array}{c}\text { Table 8: Causes for ICU Admission } \\
\text { (Total ICU Admission = 58) }\end{array}$} \\
\hline
\end{tabular}

Hypertensive disorder with 24 cases $(41.37 \%)$ was the most common indication for ICU admission; 19 cases $(32.75 \%)$ were admitted with haemorrhagic complications. In our study 10 cases $(17.24 \%)$ were presented with cardiac disease, of these 3 cases presented with CRHD and 7 cases presented with PPCM; 2 cases $(3.44 \%)$ were with viral hepatitis and AKI each and 1 case $(1.76 \%)$ with GBS.

\begin{tabular}{|c|c|c|}
\hline \multicolumn{3}{|c|}{ Maternal Death } \\
\hline & Number & MMR \\
\hline Total & 41 & 475 \\
\hline Booked (GH) & 2 & 56 \\
\hline Referral & 39 & 766 \\
\hline Booked elsewhere & 33 & 1775 \\
\hline Unbooked & 6 & 185 \\
\hline \multicolumn{2}{|c|}{ Table 9: Maternal Mortality } \\
\hline
\end{tabular}

The total number of death reported during this period was 41 with MMR of 475 , out of which only 2 were booked cases of Gandhi Hospital (MMR 56) and 39 were referral cases. Further out of this, 33 were booked elsewhere cases (MMR 1775 ) and only 6 were unbooked cases.

\begin{tabular}{|c|c|c|c|}
\hline $\begin{array}{c}\text { Less than 1 } \\
\text { Day }\end{array}$ & $\begin{array}{c}\mathbf{1} \text { to } \mathbf{3} \\
\text { Days }\end{array}$ & $\begin{array}{c}\mathbf{3} \text { to } \mathbf{7} \\
\text { Days }\end{array}$ & $\begin{array}{c}\text { More than } \mathbf{7} \\
\text { Days }\end{array}$ \\
\hline 17 & 12 & 4 & 8 \\
\hline \multicolumn{2}{|c|}{ Table 10: Admission to Death Time Interval } \\
\hline
\end{tabular}

Majority (17 out of 41) of deaths occurred on the day of admission itself; 12 deaths occurred between one and three days of admission; remaining 8 deaths occurred 7 days after admission.

\section{DISCUSSION}

In this retrospective study conducted at Gandhi Hospital, various obstetric admissions either unbooked or booked were analysed and their maternal outcome was studied. The study was conducted to analyse various factors responsible for not seeking health care or delay in seeking help. The study also tried to find implementation of desired intervention that would improve the antenatal care, thereby reducing the maternal morbidity and mortality.

Gandhi Hospital being a tertiary care centre with all the specialties and super specialties being under a single roof, most of the cases with medical and obstetrical emergencies are referred here from PHC's, CHC's, District Hospitals and other tertiary centres. Out of total 8632 near term cases admitted in Gandhi Hospital during June 2014 to May 2015; 5086 cases (59\%) were referred cases and only 3546 cases were booked cases of Gandhi Hospital. The study done by Riffat Jaleel, et al. showed almost similar incidence (47.2\%) of unbooked cases. ${ }^{2}$ 
This also shows that large number of referred cases are being received in this hospital.

Delay in seeking antenatal care was mainly due to lack of money, ignorance and transport problems, which shows that women's education and improvement of infrastructure indirectly reduces maternal morbidity and mortality. In study by Singh Priyanka, et al. self-negligence was responsible for delayed admission in $39.7 \%$ of cases followed by lack of appropriate facilities which was seen in $27.3 \%$ of cases.

Monetary and transport problems were responsible in $9.6 \%$ and $5.0 \%$ cases respectively. ${ }^{3}$ In a study by Maitra et al., the major causes for delay were lack of equipment, anaesthetic and blood banking facility at primary/community health centres (39.72\% - 43.9\%). Transport problem was responsible for delay in $14.63 \%-32.79 \%$ of cases. 4

Time interval between referral and reporting to Gandhi Hospital varied from within 6 hours to more than 24 hours. Out of 5086 referred cases, 1853 (36.43\%) were able to reach within 6 hours of referral advice. However, majority of cases 3233 (64\%) cases reached the hospital after 6 hours and many of them $(372,7.32 \%)$ reached after 24 hours. The delay in reporting was due to large distance, lack of transport, advice of referral not taken seriously by the family members, financial constraint, etc. This also demonstrates lack of facility to deal with various obstetric complications at peripheral level. Compared to this, in the study by Ayesha Khatoon et al. shows that most of the patients referred from different sources reached hospital within $6 \mathrm{hrs}$. of referral.

While 122 (52\%) patients reached hospital within 12-24 hrs. of referral, still 18 (8\%) patients had delayed arrival, i.e. after $24 \mathrm{hrs}$. of referral. 5 The leading causes of admission were previous caesarean section, hypertensive disorder of pregnancy, pre-labour rupture of membranes, anaemia and abruption. In a study by Singh Priyanka et al., $45 \%$ of cases were referred as dystocia of labour, $2.7 \%$ and $6.8 \%$ cases were referred as obstructed labour and cephalopelvic disproportion respectively. ${ }^{2}$

In another study done by Rehana Najam et al. about the clinical presentation of the patients and the common causes of admission, the leading causes were PIH (18\%), obstructed labour (10.3\%) followed by APH (8.2\%), foetal malpresentation (7.5\%) and anaemia (7.2\%). ${ }^{6}$ Lack of facility like blood bank at peripheral centres was one of the reasons for referral to higher centre. Availability of blood and blood products at peripheral centres can improve the maternal outcome.

Regarding the mode of delivery, majority of the booked and unbooked cases were delivered by SPVD, but the incidence was more in booked cases (55.02\%); 35.39\% of unbooked referrals and $42.78 \%$ of booked referrals had caesarean section compared to only $29.97 \%$ of booked cases of Gandhi Hospital. Majority of the unbooked cases underwent Emergency LSCS compared to booked cases. This high rate of Emergency LSCS among unbooked cases was due to delayed referrals from various hospitals in the late stage of labour with various complications. In a study at Lagos, South Nigeria, $27.7 \%$ of unbooked cases were delivered by Emergency LSCS compared to $12.4 \%$ of booked cases. ${ }^{7}$

Total 73 cases presented in morbid condition out of which only 9 were booked cases of Gandhi Hospital, whereas 64 were referred cases. Most of the cases referred from outside/unbooked cases presented with previous caesarean section, prolonged labour, pre-labour rupture of membrane and also preeclampsia and eclampsia, abruption, anaemia and other medical disorders leading to increased maternal morbidity. The need for blood transfusions and higher antibiotics was relatively high among the unbooked cases.

During the study period total 58 cases were admitted in ICU, out of which 51 cases were referral cases and only 7 cases were booked cases of Gandhi Hospital. The high rate of ICU admission in referral cases were due to high rate of obstetric complications reported with them. Hypertensive disorder was the most common indication for ICU admission (24 cases $=41.37 \%) ; 19$ cases (32.75\%) were admitted with haemorrhagic complications. This is similar to study by Ugochukwu V Okafor et al. where the percentage of unplanned obstetric admissions to ICU was $83 \%$ of all obstetric admissions during the study period. The major indications for unplanned admission to the ICU in this study were preeclampsia/eclampsia, obstetric haemorrhage and respiratory distress. ${ }^{8}$

The total number of maternal death reported during the study period was 41 , which correspond to MMR of 475 . The overall high MMR of hospital can be explained by the fact that it receives most of the complicated referral cases and accordingly MMR is likely to be quite high compared to state average - 134 MMR (2007 - 2009). ${ }^{9}$ A comparison of MMR between referral cases and booked cases of hospital shows that the MMR of referral cases is 776 , which is quite high compared with MMR of booked cases, which is only 56. Further the MMR of referrals which were booked elsewhere was 1775, which indicates that high risk cases are referred to our hospital. This was consistent with a study done at Nepal, which had 16 maternal deaths out of 2128 admissions (None of them being booked).10

Out of total 41 maternal deaths reported during the period, 17 deaths occurred within 24 hours and 12 deaths occurred between 1 to 3 days. The reason for the condition becoming critical may be due to delay in seeking the treatment or inadequate facilities at peripheral centre. Ignorance, illiteracy, poverty and lack of family support for patients reaching to hospital in critical condition. This shows that delayed referral had an adverse effect on maternal morbidity and mortality. Regular antenatal check-up, screening of high risk cases, availability of skilled personnel and availability of blood in peripheral centre has major role in improving maternal outcome.

\section{CONCLUSION}

Quality of antenatal check-up has a direct bearing on the Obstetric Emergencies, which are the leading causes of maternal morbidity and mortality, particularly in developing countries. Very high referral cases (About 60\%) to the hospital indicates that there is urgent need to strengthen primary and secondary healthcare infrastructure. The major indications for Admission/Referral cases into Gandhi Hospital in my study were Hypertensive disorders of pregnancy, Anaemia, APH besides obstetric indications like pre-labour rupture of membrane, prolonged labour and previous LSCS.

Among all the cases of referrals, some of them took more than 24 hours to reach hospital due to long distance, delay in transportation, financial constraints, intermediary referrals and lack of family support. Increased incidence of complications due to time delay clearly demonstrates that 
quick transfer of patients to higher centres reduces the maternal morbidity and mortality.

The incidence of Emergency LSCS, maternal morbidity, ICU admission and mortality was higher among the unbooked cases. Poor utilization of antenatal care and also the lack of experienced personnel in the peripheries like Obstetrician, Anaesthetist and other Speciality doctors, lack of blood bank facility, delay in transportation are important factors associated with increased maternal morbidity and mortality.

Finally, to conclude regular antenatal care by health workers and ASHA workers and meticulous supervision of their duties will help in early diagnosis and timely referral. Utilization of antenatal care services, availability of blood in peripheral centres, timely referral in high risk cases, maternal stabilization before and during transfer and also intensive monitoring of women with complications throughout hospitalization will help in reducing maternal morbidity and mortality.

\section{REFERENCES}

1. Ndiweni Q, Buchmann EJ. Unbooked mothers and their babies-what causes the poor outcomes? S Afr Med J 1998;88(2):192, 195-199.

2. Riffat Jaleel, Ayesha Khan. Obstetric morbidity in the booked versus non-booked patients-a comparative study at lyari general hospital. Pakistan Journal of Surgery 2008;24(3):196-202.

3. Singh Priyanka, Jacob Shyla, Nandanamudi Lakshmi Sowbhagaya. The status of rural reproductive health and its implications on feto-maternal outcome at tertiary care centre scholars. Journal of Applied Medical Sciences 2015;3(5B):1941-1945.
4. Maitra N. Utilisation of referral services by a high risk pregnant population. Journal of OBG of India 1994;365369.

5. Ayesha Khatoon, Syeda Fariha Hasny, Saima Irshad, et al. An audit of obstetrics referrals to abbasi shaheed hospital. Pak J Surg 2011;27(4):304-308.

6. Rehana Najam, Sarika Gupta, Hasnahana Chowdhury. Pattern of obstetrical emergencies and fetal outcomes in a tertiary care centre. Acta Medica International 2015;2(1):105-110.

7. Fabamwo A, Akinola D, Mojoyinola 0 . The tragic consequences of unsupervised pregnancies among patient referred to a tertiary maternity unit in lagos south west Nigeria. The internet journal of tropical medicine 2010;7(1):p 9.

8. Ugochukwu V Okafor, Efenae R Efetie, Adaobi Amucheazi. Risk factors for maternal deaths in unplanned obstetric admissions to the intensive care unit-lessons for subSaharan Africa. African Journal of Reproductive Health 2011;15(4):51-54.

9. Maternal mortality ratio India. Department of health \& family welfare 2007-2009.

10. Pokharel HP, Lama GJ, Banerjee B, et al. Maternal and perinatal outcome among the booked and unbooked pregnancies from catchment area of BP koirala institute of health sciences, Nepal. Kathmandu Univ Med J (KUMJ) 2007;5(2):173-6. 